\title{
Low-Temperature Heat Capacities and Thermodynamic Functions of Some Platinum and Palladium Group Chalcogenides. I. Monochalcogenides; PtS, PtTe, and PdTe $\dagger$
}

\author{
Fredrix Grønvold and Torkild Thurmann-MoE \\ Chemical Instithte A, University of Oslo, Blindern, Norway \\ AND \\ Edgar F. Westrum, Jr., and Elfreda Chang \\ Department of Chemistry, University of Michigan, Ann Arbor, Michigan
}

(Received February 16, 1961)

\begin{abstract}
Heat capacities of platinum monosulfide, platinum monotelluride, and palladium monotelluride were measured in the range $5-350^{\circ} \mathrm{K}$. They show the normal sigmoidal temperature dependence with no evidence of transitions or other anomalies. The derived heat-capacity equations were integrated. Values of heat capacities, entropy and enthalpy increments, and of the free-energy function are tabulated for selected temperatures. At $298.15^{\circ} \mathrm{K}$, the third-law entropies are $13.16 \mathrm{cal} \mathrm{gfw} \mathrm{w}^{-1}{ }^{\circ} \mathrm{K}^{-1}$ for $\mathrm{PtS}, 19.41 \mathrm{cal} \mathrm{gfw}^{-1}{ }^{\circ} \mathrm{K}^{-1}$ for $\mathrm{PtTe}$, and $21.42 \mathrm{cal} \mathrm{gfw}^{-1}{ }^{\circ} \mathrm{K}^{-1}$ for PdTe. The new data on PtS have been correlated with existing decomposition-pressure data to evaluate $\Delta H f, \Delta F f$, and $\Delta S f 298.15^{\circ} \mathrm{K}$. Entropies for other platinum-metal monochalcogenides were estimated.
\end{abstract}

\section{INTRODUCTION}

$\mathbf{T}$ HE present paper is concerned with sulfides, selenides, and tellurides of the platinum and palladium. For these chalcogenides, recently surveyed by Haraldsen, ${ }^{1}$ no heat-capacity measurements have been reported. Such data are desirable, however, for evaluation of the entropies of the chalcogenides with a better precision than has been possible in the past, and to get an insight into the causes of variations in heat capacity with the nature of the compounding elements and the properties of the compound.

Excluding the oxides, no monochalcogenides are known with certainty for ruthenium, osmium, and iridium; for the remaining metals of the platinum and palladium groups, the following compounds with exact (or approximate) composition $\mathrm{Me} X$ have been found: $\mathrm{Rh}_{9} \mathrm{~S}_{8} \quad[\mathrm{cu}, a=9.9116]^{2}$; RhTe [hex B8, $a=3.99$, $c=5.66]^{3} ;$ PdS $[\operatorname{tetr} B 34, a=6.4287, c=6.6082]^{4}$; $\mathrm{Pd}_{9} \mathrm{Se}_{8}[\mathrm{cu}, a=10.6060]^{2}$; PdSe [tetr B34, $a=6.73$, $c=6.91]^{5} ; \quad \mathrm{PdTe}[\text { hex } B 8, a=4.1521, c=5.6719]^{4}$; PtS [tetr $B, a=3.4700, c=6.1096]^{6} ; \mathrm{Pt}_{10} \mathrm{Se}_{8}$ [monocl, $\left.a=6.5806, b=4.6248, c=11.145, \beta=78.40^{\circ}\right]^{6} ; \mathrm{PtTe}$ [orthorh, $a=6.6144, b=5.6360, c=11.865] .{ }^{6}$ The structures and lattice dimensions $(A)$ have been included for each substance.

$\dagger$ This work was supported in part by the Division of Research of the U. S. Atomic Energy Commission.

${ }^{1} \mathrm{H}$. Haraldsen, Plenary Lecture, XVI. Congress of the IUPAC, Paris, 1957, reprinted in Experientia Supple. VII, 165 (1957), and Mémoires présentès à la Section de Chimie Minérale, SEDES, Paris, 1958.

2. K jekshus, Acta Chem. Scand. 14, 1623 (1960).

${ }^{3}$ S. Geller, I. Am. Chem. Soc. 77, 2641 (1955)

${ }^{4}$ F. Grønvold and E. Røst, Acta Chem. Scand. 10, 1620 (1956).

$s \mathrm{~K}$. Schubert, H. Breimer, W. Burkhardt, E. Günzel, R. Haufler, H. L. Lukas, H. Vetter, J. Wegst, and M. Wilkens, Naturwissenschaften 44, 229 (1957).

${ }^{6}$ F. Grønvold, H. Haraldsen, and A. Kjekshus, Acta Chem. Scand. 14, $1879(1960)$.
Three of these chalcogenides were chosen for the present investigation, $\mathrm{PtS}$ as representative for the tetragonal square-coordinated structures, $\mathrm{PtTe}$ for a low-symmetric structure, and PdTe for the NiAs (B8)type structure. Their heat capacities were determined and the thermodynamic functions obtained. On the basis of these and other data, standard entropies of the remaining chalcogenides are estimated.

\section{EXPERIMENTAL}

\section{Preparation of the Samples}

The samples were prepared from high-purity elements. The platinum, which came from The Mond Nickel Company, Ltd, contained the following impurities (in ppm): $\mathrm{Au}(1), \mathrm{Fe}(<10),(\mathrm{Pb}<10), \mathrm{Pd}(7)$, volatile material (90). The palladium, also from the same company, contained: $\mathrm{Ag}(30), \mathrm{Au}(70), \mathrm{Fe}(20)$, $\mathrm{Pb}(2), \mathrm{Pt}(50), \mathrm{Rh}(10)$, insoluble (principally $\mathrm{SiO}_{2}$ ) (60), volatile material (120). Before use, both the palladium and platinum were degassed under high vacuum at $600^{\circ} \mathrm{C}$ for four hours. Sulfur cryst. puriss. from Schering-Kahlbaum A.G. was purified before use by techniques similar to those described by v. Wartenberg $^{7}$ and Skjerven. ${ }^{8}$ The sulfur was first heated by means of a submerged heater with a surface temperature of about $800^{\circ} \mathrm{C}$ until the carbon deposition ceased; this required about three weeks. Thereafter, it was purified by fractional distillation.

The tellurium was a special product with a stated purity of $99.999 \%$ from the American Smelting and Refining Company, in which no impurities had been detected by spectrographic methods.

${ }^{7}$ H. v. Wartenberg, Z. anorg. u. allgem. Chem. 286, 243 (1956).

${ }^{5}$ O. Skjerven, Z. anorg. u. allgem. Chem. 291, 325 (1957). 
TABLE I. Heat capacities of platinum and palladium monochalcogenides; in calories/(gram formula weight ${ }^{\circ} \mathrm{K}$ ).

\begin{tabular}{|c|c|c|c|c|c|}
\hline$T,{ }^{\circ} \mathrm{K}$ & $C_{p}$ & $T,{ }^{\circ} \mathrm{K}$ & $C_{p}$ & $T,{ }^{\circ} \mathrm{K}$ & $C_{p}$ \\
\hline \multicolumn{6}{|c|}{ PtS; gram formula weight $=227.16 \mathrm{~g}$} \\
\hline \multicolumn{2}{|c|}{ Series I } & 21.32 & 0.6224 & 174.93 & 8.177 \\
\hline 54.00 & 3.074 & 23.11 & 0.7472 & 183.61 & 8.388 \\
\hline 59.79 & 3.429 & 24.99 & 0.8861 & 192.20 & 8.645 \\
\hline 65.98 & 3.783 & 27.16 & 1.055 & 201.20 & 8.849 \\
\hline 73.12 & 4.152 & 29.67 & 1.259 & 210.37 & 9.033 \\
\hline 80.35 & 4.511 & 32.54 & 1.494 & 219.30 & 9.220 \\
\hline 87.24 & 4.843 & 35.75 & 1.755 & 228.33 & 9.384 \\
\hline 94.52 & 5.175 & 39.16 & 2.026 & 237.28 & 9.550 \\
\hline & & & 2.308 & 246.33 & 9.712 \\
\hline \multicolumn{2}{|c|}{ Series II } & 46.97 & 2.603 & 255.30 & 9.836 \\
\hline 6.01 & 0.014 & 51.33 & 2.910 & 263.94 & 9.961 \\
\hline 6.99 & 0.025 & \multirow{2}{*}{\multicolumn{2}{|c|}{ Series III }} & 272.49 & 10.066 \\
\hline 7.77 & 0.034 & & & 260.99 & 9.897 \\
\hline 8.80 & 0.052 & 94.19 & 5.158 & 269.64 & 10.023 \\
\hline 10.11 & 0.084 & 101.10 & 5.465 & 278.25 & 10.136 \\
\hline 11.47 & 0.1188 & 108.84 & 5.805 & 286.91 & 10.248 \\
\hline 12.74 & 0.1610 & 117.40 & 6.165 & 295.57 & 10.343 \\
\hline 13.98 & 0.2091 & 125.65 & 6.499 & 304.40 & 10.442 \\
\hline 15.32 & 0.2684 & 132.91 & 6.791 & 313.45 & 10.546 \\
\hline 16.74 & 0.3408 & 141.06 & 7.093 & 322.60 & 10.610 \\
\hline & 0.4236 & 149.44 & 7.391 & 331.86 & 10.675 \\
\hline \multirow{2}{*}{19.70} & 0.5143 & 157.89 & 7.676 & 341.21 & 10.755 \\
\hline & & 166.37 & 7.939 & 347.63 & 10.821 \\
\hline
\end{tabular}

PtTe; gram formula weight $=322.70 \mathrm{~g}$

\begin{tabular}{rrrrrr}
\multicolumn{5}{c}{ Series I } & \multicolumn{3}{c}{ Series II } & 45.52 & 4.267 \\
67.93 & 6.799 & & & 50.34 & 4.875 \\
73.71 & 7.301 & 4.92 & 0.019 & 55.60 & 5.503 \\
81.17 & 7.889 & 5.83 & 0.031 & 61.37 & 6.141 \\
88.74 & 8.409 & 6.78 & 0.049 & 67.61 & 6.758 \\
96.25 & 8.812 & 7.76 & 0.077 & \multicolumn{2}{c}{ Series III } \\
103.91 & 9.173 & 7.67 & 0.076 & & \\
111.67 & 9.508 & 8.73 & 0.1178 & 261.12 & 11.725 \\
119.76 & 9.791 & 9.84 & 0.1751 & 270.18 & 11.783 \\
128.22 & 10.054 & 10.83 & 0.2239 & 279.15 & 11.826 \\
136.77 & 10.287 & 11.95 & 0.2857 & & \\
142.66 & 10.433 & 13.19 & 0.3727 & & \\
151.34 & 10.599 & 14.46 & 0.4735 & Series IV \\
160.22 & 10.774 & 15.76 & 0.5841 & & \\
169.23 & 10.905 & 17.12 & 0.7091 & 259.71 & 11.740 \\
178.35 & 11.034 & 18.64 & 0.8600 & 268.84 & 11.781 \\
187.73 & 11.159 & 20.32 & 1.033 & 277.99 & 11.827 \\
197.16 & 11.261 & 22.16 & 1.235 & 287.14 & 11.876 \\
206.61 & 11.353 & 24.14 & 1.463 & 296.08 & 11.927 \\
216.02 & 11.428 & 26.30 & 1.728 & 304.91 & 11.971 \\
225.33 & 11.497 & 28.40 & 1.991 & 313.80 & 11.985 \\
234.50 & 11.576 & 30.92 & 2.319 & 322.95 & 12.009 \\
243.63 & 11.650 & 34.06 & 2.737 & 332.36 & 12.053 \\
252.67 & 11.684 & 37.40 & 3.183 & 340.92 & 12.098 \\
216.61 & 11.761 & 41.20 & 3.695 & 347.07 & 12.118 \\
\hline \multicolumn{7}{c}{ PdTe; gram formula weight=234.01 g } \\
\hline
\end{tabular}

Platinum monosulfide was synthesized in two steps. First, $\mathrm{PtS}_{2}$ was prepared by heating appropriate amounts of the elements in an evacuated and sealed silica tube at $750^{\circ} \mathrm{C}$ for one day. The sintered product was crushed and then heated with stoichiometric amounts of finely divided platinum at $900^{\circ} \mathrm{C}$ for two days. The resulting dark-grey powder with a bluish cast was annealed at $500^{\circ} \mathrm{C}$ for two days and finally cooled to room temperature over a period of seven days.

Platinum monotelluride was prepared by allowing the elements to react at $1000^{\circ} \mathrm{C}$ for six hours, and then raising the temperature to $1200^{\circ} \mathrm{C}$ in order to melt the sample. After about one hour at this temperature, the furnace was shut off and the sample cooled to room temperature overnight. The melt was broken into flaky fragments with lead-grey metallic luster. These fragments were annealed at $500^{\circ} \mathrm{C}$ for seven days and slowly cooled to room temperature over another seven days.

Palladium monotelluride was prepared from stoichiometric amounts of palladium and tellurium heated in an evacuated and sealed silica tube to $800^{\circ} \mathrm{C}$. It was kept in the molten state for about two hours and, after cooling, was broken into fragments of several millimeters in dimension with splendent pale-yellow metallic luster. After annealing for seven days at $500^{\circ} \mathrm{C}$, the sample was cooled to room temperature over a period of two days.

$\mathrm{X}$-ray photographs were taken of the samples in powder cameras of $11.46 \mathrm{~cm}$ diam utilizing asymmetric film mounting. The lattice constants corresponded, within the limits of experimental error, to those reported earlier for these compounds, ${ }^{4,6}$ and no lines from foreign phases could be observed.

\section{Cryostat and Calorimeter}

The design and operation of the Mark I cryostat for low-temperature adiabatic calorimetry has been described. ${ }^{9}$ A completely gold-plated copper calorimeter, W-7 (similar to W-5 in design except that the volume was only $40.33 \mathrm{~cm}^{3}$ and there were only four vanes) was employed. The same heater, thermometer, amount of indium-tin solder for sealing, and amount of Apiezon- $T$ grease for thermal contact between the heater, thermometer, and calorimeter were used for all measurements. The capsule-type platinum resistance thermometer (laboratory designation A-3) was calibrated by the National Bureau of Standards, and the temperatures are believed to correspond with the thermodynamic scale within $0.03^{\circ}$ from $10-90^{\circ} \mathrm{K}$, and within $0.04^{\circ}$ from $90-350^{\circ} \mathrm{K}$. Below $10^{\circ} \mathrm{K}$, a provisional scale for temperature was used. Calibrated instruments were used in the determination of all measured quantities. 


\section{Procedure}

The calorimeter was loaded with sample, evacuated, filled with gaseous helium at $8 \mathrm{~cm} \mathrm{Hg}$ pressure at $26^{\circ} \mathrm{C}$ (to provide thermal contact between the calorimeter and sample), and sealed. After adjusting the weights of solder and grease used, it was placed in the cryostat. The weights of samples used were $172.448 \mathrm{~g}$ of $\mathrm{PtS}$, $196.792 \mathrm{~g}$ of PtTe, and $179.866 \mathrm{~g}$ of PdTe.

\section{COMPUTATION AND RESULTS}

The experimental heat capacity results for the three chalcogenide samples are presented in Table $I$ in chronological order, so that temperature increments for individual determinations may be inferred from adjacent temperatures. The values are expressed in terms of the defined thermochemical calorie, equal to 4.1840 abs $j$. The ice point is taken as $273.15^{\circ} \mathrm{K}$ and the gram formula weights of $\mathrm{PtS}, \mathrm{PtTe}$, and $\mathrm{PdTe}$ as $227.16,322.70$, and $234.01 \mathrm{~g}$, respectively. The densities are found to be $10.09 \mathrm{~g} \mathrm{~cm}^{-3}$ for PtS, $12.01 \mathrm{~g} \mathrm{~cm}^{-3}$ for PtTe (both by pycnometric measurement ${ }^{6}$ ), and 9.186 $\mathrm{g} \mathrm{cm}^{-3}$ for PdTe (from x-ray diffraction data).

The heat capacity of the calorimeter, separately determined, represents a maximum at $350^{\circ} \mathrm{K}$ of $40 \%$, and $34 \%$ of the total heat capacities measured when filled with the PtTe and PdTe samples, respectively. The minimum contribution of the empty calorimeter occurs at $10^{\circ} \mathrm{K}$, where it represents $14 \%$ of the total heat capacity for both compounds. At $6^{\circ} \mathrm{K}$, it represents $20 \%$ of the total. The contribution for the PtS sample reaches a maximum of $43 \%$ at $90^{\circ} \mathrm{K}$ and a minimum of $23 \%$ at $14^{\circ} \mathrm{K}$. At $6^{\circ} \mathrm{K}$, the value is $30 \%$; and at $350^{\circ} \mathrm{K}$, it is $37 \%$ of the total heat capacity.

An analytically generated "curvature" correction for the finite temperature increments of the measurements is added to each of the observed values of $\Delta H / \Delta T$. The derivatives $(d H / d T)$ resulting from this correction are equal to $C_{p}$ (or to $C_{\text {sat }}$ ) within the limits of experimental error.

The heat capacity vs temperature curve in Fig. 1 is of the usual sigmoid shape with no anomalous departures. Above $30^{\circ} \mathrm{K}$, most of the points in Table I deviate from a smooth curve, discussed below, by less than $0.007 \mathrm{cal}$ mole $\mathrm{e}^{-1}$. Below $30^{\circ} \mathrm{K}$, the deviations become larger due to the smaller absolute heat capacity, the smaller temperature intervals of measurement, and the decreased sensitivity of the thermometer.

The values of $C_{p}, S^{\circ}-S_{0}^{\circ}, H^{\circ}-H_{0}^{\circ}, \quad$ and $-\left(F^{\circ}-H_{0}^{\circ}\right) / T$ at selected temperatures are given in Table II. The estimated probable error in these functions is less than $0.1 \%$ above $100^{\circ} \mathrm{K}$. To make the table internally consistent, an additional figure is given over that justified by experimental accuracy. An IBM 704 digital computer was used to generate a least-squares polynomial in temperature from the curvature-corrected heat-capacity data for the region above $25^{\circ} \mathrm{K}$ and compared with a large-scale plot of the molal heatcapacity vs temperature for the experimental points.

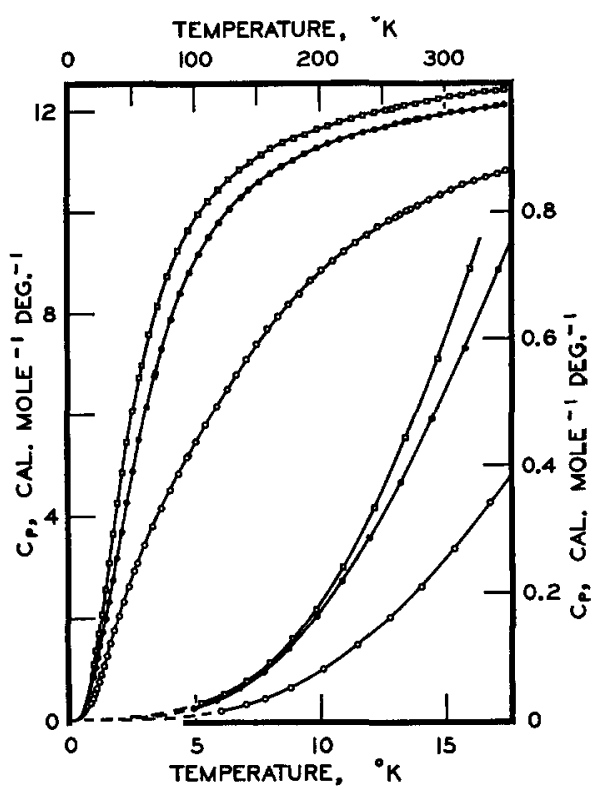

FIG. 1. Heat capacities of the monochalcogenides on a gram formula weight basis: $O$ represents $P t S, O$ represents $P t T e$, and $\square$ represents PdTe.

The values of the heat capacity presented in Table II are read from the plot below $25^{\circ} \mathrm{K}$. Above this temperature, values from both the plot and the smooth polynomial curve are identical. Extrapolation is made with a Debye $T^{3}$ function below $6^{\circ} \mathrm{K}$. Integration of the experimental $C_{p}$ data was used to derive the entropy and enthalpy values. The free-energy function is computed from these results.

\section{DISCUSSION}

The only compound for which some comparison of thermodynamic data can be made is $\mathrm{PtS}$. On the basis of decomposition-pressure measurements by Biltz and $\mathrm{Juza}^{10}$ in the $\mathrm{PtS} / \mathrm{Pt}$ range at the temperatures 1060 , 1110 , and $1186^{\circ} \mathrm{C}$, Kelley ${ }^{11}$ calculated the standard value of the entropy of $\mathrm{PtS}$ at $298^{\circ} \mathrm{K}$ to be $S^{\circ}=12.2$ cal $\mathrm{gfw}^{-1}{ }^{\circ} \mathrm{K}^{-1}$. This was done before heat-capacity data on PtS existed, and the heat-capacity equation assumed by Kelley $C_{p}=11.14+2.86 \times 10^{-3} \mathrm{~T} \mathrm{cal} \mathrm{gfw}^{-1}$ ${ }^{\circ} \mathrm{K}^{-1}\left(298-1000^{\circ} \mathrm{K}\right)$, resulted in an entropy value in fair accord with that determined in this research: $S^{\circ}=13.16 \mathrm{cal} \mathrm{gfw}^{-1}{ }^{\circ} \mathrm{K}^{-1}$.

Since it should now be possible to deduce a better high-temperature heat-capacity temperature relationship for $\mathrm{PtS}$, and also because Biltz and Juza appear to have included some questionable values in the low sulfur region (those for $\mathrm{Pt} \mathrm{S}_{0.02}, \mathrm{PtS}_{0.06}$, and $\mathrm{PtS}_{0.07}$ ) in their average values, a new calculation of the thermodynamic functions was performed.

\footnotetext{
${ }^{10} \mathrm{~W}$. Biltz and R. Juza, Z. anorg. u. allgem. Chem. 190, 161 (1930)

${ }^{11} \mathrm{~K} . \mathrm{K}$. Kelley, "Contributions to the data on theoretical metallurgy. VII.," U. S. Bureau of Mines Bulletin 406, Washington, D. C. (1937); cf. K. K. Kelley, "Contributions to the data on theoretical metallurgy. XI.," U. S. Bureau of Mines Bulletin 477, Washington, D. C. (1950).
} 
TABLE II. Thermodynamic properties of platinum and palladium monochalcogenides.

\begin{tabular}{|c|c|c|c|c|c|c|c|c|c|}
\hline$T,{ }^{\circ} \mathrm{K}$ & $\begin{array}{c}C_{p} \\
\mathrm{cal} / \mathrm{gfw}\end{array}$ & $\begin{array}{c}S^{\circ}-S_{0}{ }^{\circ} \\
\mathrm{cal} / \mathrm{gfw}{ }^{\circ} \mathrm{K}\end{array}$ & $\begin{array}{l}H^{\circ}-H_{0}^{\circ} \\
\mathrm{cal} / \mathrm{gfw}\end{array}$ & $\begin{array}{c}-\left(F^{\circ}-H_{0}^{\circ}\right) / T \\
\mathrm{cal} / \mathrm{gfw}^{\circ} \mathrm{K}\end{array}$ & $T,{ }^{\circ} \mathrm{K}$ & $\begin{array}{c}C_{p} \\
\mathrm{cal} / \mathrm{gfw}{ }^{\circ} \mathrm{K}\end{array}$ & $\begin{array}{c}S^{\circ}-S_{0}{ }^{\circ} \\
\mathrm{cal} / \mathrm{gfw}{ }^{\circ} \mathrm{K}\end{array}$ & $\begin{array}{c}H^{\circ}-H_{0}^{\circ} \\
\mathrm{cal} / \mathrm{gfw}\end{array}$ & $\begin{array}{c}-\left(F^{\circ}-H_{0}^{\circ}\right) / T \\
\text { cal } / \mathrm{gfw}^{\circ} \mathrm{K}\end{array}$ \\
\hline \multicolumn{5}{|c|}{$\mathrm{PtS}$; gram formula weight $=227.16 \mathrm{~g}$} & \multicolumn{5}{|c|}{ PtTe; gram formula weight $=322.70 \mathrm{~g}$} \\
\hline 5 & 0.008 & $(0.003)$ & $(0.010)$ & $(0.001)$ & 150 & 10.58 & 11.615 & 949.8 & 5.283 \\
\hline 10 & 0.077 & 0.024 & 0.185 & 0.006 & 160 & 10.77 & 12.304 & 1056.6 & 5.700 \\
\hline 15 & 0.253 & 0.085 & 0.968 & 0.020 & 170 & 10.92 & 12.962 & 1165.1 & 6.108 \\
\hline 20 & 0.533 & 0.194 & 2.90 & 0.050 & 180 & 11.06 & 13.590 & 1275.1 & 6.507 \\
\hline 25 & 0.888 & 0.350 & 6.43 & 0.093 & 190 & 11.19 & 14.192 & 1386.3 & 6.895 \\
\hline 30 & 1.286 & 0.547 & 11.85 & 0.152 & 200 & 11.29 & 14.768 & 1498.7 & 7.275 \\
\hline 35 & 1.694 & 0.776 & 19.30 & 0.224 & 210 & 11.38 & 15.321 & 1612.1 & 7.645 \\
\hline 40 & 2.091 & 1.028 & 28.76 & 0.309 & 220 & 11.46 & 15.853 & 1726.3 & 8.006 \\
\hline 45 & 2.464 & 1.296 & 40.15 & 0.404 & 230 & 11.54 & 16.364 & 1841.3 & 8.358 \\
\hline 50 & 2.814 & 1.574 & 53.36 & 0.507 & 240 & 11.61 & 16.856 & 1957.0 & 8.702 \\
\hline 60 & 3.444 & 2.144 & 84.73 & 0.732 & 250 & 11.67 & 17.331 & 2073.4 & 9.038 \\
\hline 70 & 3.993 & 2.717 & 121.97 & 0.975 & 260 & 11.73 & 17.790 & 2190.4 & 9.366 \\
\hline 80 & 4.494 & 3.284 & 164.46 & 1.228 & 270 & 11.79 & 18.234 & 2308.0 & 9.686 \\
\hline 90 & 4.969 & 3.841 & 211.79 & 1.487 & 280 & 11.85 & 18.664 & 2426.2 & 9.999 \\
\hline 100 & 5.417 & 4.387 & 263.72 & 1.750 & 290 & 11.90 & 19.081 & 2544.9 & 10.305 \\
\hline 110 & 5.852 & 4.924 & 320.09 & 2.014 & 300 & 11.94 & 19.485 & 2664.1 & 10.604 \\
\hline 120 & 6.272 & 5.452 & 380.74 & 2.279 & 350 & 12.14 & 21.338 & 3265.5 & 12.008 \\
\hline 130 & 6.675 & 5.970 & 445.51 & 2.543 & 273.15 & 11.81 & 18.37 & 2345 & 9.78 \\
\hline 140 & 7.055 & 6.479 & 514.2 & 2.806 & 298.15 & 11.93 & 19.41 & 2642 & 10.55 \\
\hline 150 & 7.410 & 6.978 & 586.5 & 3.067 & & & & & \\
\hline 160 & 7.742 & 7.467 & 662.3 & 3.327 & \multirow{2}{*}{\multicolumn{5}{|c|}{ PdTe; gram formula weight $=234.01 \mathrm{~g}$}} \\
\hline 170 & 8.045 & 7.945 & 741.3 & 3.585 & & & & & \\
\hline 180 & 8.324 & 8.413 & 823.1 & 3.840 & & & & & \\
\hline 190 & 8.585 & 8.870 & 907.7 & 4.093 & 5 & $(0.024)$ & $(0.008)$ & $(0.030)$ & $(0.002)$ \\
\hline 200 & 8.820 & 9.316 & 994.7 & 4.343 & 10 & 0.184 & 0.060 & 0.451 & 0.015 \\
\hline 210 & 9.034 & 0.752 & 1083.9 & 4.590 & 15 & 0.602 & 0.205 & 2.31 & 0.051 \\
\hline 220 & 9.231 & 10.177 & 1175.3 & 4.834 & 20 & 1.230 & 0.460 & 6.82 & 0.119 \\
\hline 230 & 9.419 & 10.592 & 1268.6 & 5.076 & 25 & 2.004 & 0.816 & 14.85 & 0.221 \\
\hline 240 & 0.597 & 10.996 & 1363.7 & 5.314 & 30 & 2.862 & 1.257 & 27.01 & 0.356 \\
\hline 250 & 9.761 & 11.391 & 1460.5 & 5.549 & 35 & 3.728 & 1.763 & 43.49 & 0.520 \\
\hline 260 & 9.907 & 11.777 & 1558.8 & 5.781 & 40 & 4.559 & 2.315 & 64.21 & 0.710 \\
\hline 270 & 10.04 & 12.153 & 1658.5 & 6.011 & 45 & 5.321 & 2.896 & 88.93 & 0.920 \\
\hline 280 & 10.16 & 12.520 & 1759.5 & 6.236 & 50 & 6.019 & 3.494 & 117.33 & 1.148 \\
\hline 290 & 10.28 & 12.879 & 1861.7 & 6.459 & 60 & 7.209 & 4.701 & 183.70 & 1.639 \\
\hline 300 & 10.39 & 13.230 & 1965.1 & 6.679 & 70 & 8.120 & 5.884 & 260.56 & 2.162 \\
\hline 350 & 10.81 & 14.867 & 2496.4 & 7.734 & 80 & 8.841 & 7.018 & 345.57 & 2.698 \\
\hline 273.15 & 10.07 & 12.27 & 1690 & 6.08 & 90 & 9.410 & 8.093 & 436.89 & 3.239 \\
\hline 298.15 & 10.37 & 13.16 & 1946 & 6.64 & 100 & 9.842 & 9.107 & 533.2 & 3.775 \\
\hline \multirow{2}{*}{\multicolumn{5}{|c|}{ PtTe; gram formula weight $=322.70 \mathrm{~g}$}} & 110 & 10.19 & 10.062 & 633.4 & \\
\hline & & & & & 120 & 10.48 & 10.962 & $\begin{array}{l}736.8 \\
842.8\end{array}$ & $\begin{array}{l}4.822 \\
5.327\end{array}$ \\
\hline & & & & & 140 & 10.92 & 12.612 & 951.1 & 5.819 \\
\hline 5 & $(0.020)$ & $(0.007)$ & $(0.025)$ & $(0.002)$ & 150 & 11.09 & 13.371 & 1061.1 & 6.297 \\
\hline 10 & 0.170 & 0.055 & 0.416 & 0.013 & 160 & 11.24 & 14.092 & 1172.8 & 6.762 \\
\hline 15 & 0.518 & 0.184 & 2.07 & 0.046 & 170 & 11.37 & 14.777 & 1285.8 & 7.214 \\
\hline 20 & 1.002 & 0.397 & 5.82 & 0.106 & 180 & 11.47 & 15.430 & 1400.0 & 7.652 \\
\hline 25 & 1.566 & 0.679 & 12.20 & 0.191 & 190 & 11.57 & 16.053 & 1515.2 & 8.078 \\
\hline 30 & 2.198 & 1.020 & 21.60 & 0.300 & 200 & 11.66 & 16.648 & 1631.4 & 8.492 \\
\hline 35 & 2.861 & 1.408 & 34.24 & 0.430 & 210 & 11.73 & 17.219 & 1748.3 & 8.894 \\
\hline 40 & 3.534 & 1.835 & 50.24 & 0.579 & 220 & 11.81 & 17.767 & 1866.0 & 9.285 \\
\hline 45 & 4.197 & 2.290 & 69.58 & 0.743 & 230 & 11.87 & 18.293 & 1984.5 & 9.665 \\
\hline 50 & 4.833 & 2.765 & 92.17 & 0.922 & 240 & 11.94 & 18.800 & 2103.5 & 10.035 \\
\hline 60 & 5.995 & 3.751 & 146.43 & 1.311 & 250 & 12.00 & 19.288 & 2223.2 & 10.396 \\
\hline 70 & 6.983 & 4.751 & 211.45 & 1.731 & 260 & 12.06 & 19.760 & 2343.5 & 10.747 \\
\hline 80 & 7.802 & 5.739 & 285.52 & 2.170 & 270 & 12.11 & 20.216 & 2464.4 & 11.089 \\
\hline 90 & 8.472 & 6.698 & 367.00 & 2.620 & 280 & 12.16 & 20.658 & 2585.7 & 11.423 \\
\hline 100 & 9.009 & 7.619 & 454.69 & 3.075 & 290 & 12.20 & 21.085 & 2707.5 & 11.749 \\
\hline 110 & 9.445 & 8.499 & 546.8 & 3.528 & 300 & 12.24 & 21.499 & 2829.7 & 12.067 \\
\hline 120 & 9.802 & 9.337 & 643.2 & 3.977 & 350 & 12.42 & 23.401 & 3446.6 & 13.553 \\
\hline 130 & 10.11 & 10.134 & 742.8 & 4.421 & 273.15 & 12.12 & 20.36 & 2502 & 11.20 \\
\hline 140 & 10.36 & 10.893 & 845.1 & 4.856 & 298.15 & 12.23 & 21.42 & 2807 & 12.01 \\
\hline
\end{tabular}

In the absence of any high-temperature enthalpy data on PtS, we will assume the same heat capacity at $1000^{\circ} \mathrm{K}$ as Kelley did $\left(C_{p}=14 \mathrm{cal} \mathrm{gfw}^{-1}{ }^{\circ} \mathrm{K}^{-1}\right)$ and construct a heat capacity curve which, in addition, goes through our points at 300 and $350^{\circ} \mathrm{K}$ and obeys the
Maier and Kelley ${ }^{12}$ relationship $C_{p}=A+B T+C T^{-2}$. For the reaction considered,

$$
2 \mathrm{PtS}(\mathrm{s})=2 \mathrm{Pt}(\mathrm{s})+\mathrm{S}_{2}(\mathrm{~g}) \text {, }
$$

${ }^{12}$ C. G. Maier and K. K. Kelley, J. Am. Chem. Soc. 54, 3243 (1932). 
the following heat-capacity equations (in cal $\mathrm{gfw}^{-1}{ }^{\circ} \mathrm{K}^{-1}$ ) are chosen:

$$
\begin{aligned}
& \mathrm{PtS}(\mathrm{s}), C_{p}=9.97+4.11 \times 10^{-3} T-0.73 \times 10^{5} T^{-2}, \\
& \operatorname{Pt}(\mathrm{s}),{ }^{13} C_{p}=5.81+1.26 \times 10^{-3} T+0.06 \times 10^{5} T^{-2}, \\
& \mathrm{~S}_{2}(\mathrm{~g}),{ }^{13} C_{p}=8.72+0.16 \times 10^{-3} T-0.90 \times 10^{5} T^{-2} .
\end{aligned}
$$

Thus,

$$
\begin{aligned}
& \Delta C_{p}= 0.40-5.54 \times 10^{-3} T+0.68 \times 10^{5} T^{-2} \\
& \Delta H_{T}{ }^{\circ}=\Delta H_{0}+0.40 T-2.77 \times 10^{-3} T^{2}-0.68 \times 10^{5} T^{-1}, \\
& \Delta F_{T}^{\circ}=-R T \ln K=\Delta H_{0}-0.40 T \ln T+2.77 \\
& \times 10^{-3} T^{2}-0.34 \times 10^{5} T^{-1}+I T,
\end{aligned}
$$

and

$$
\begin{aligned}
\left(\Delta H_{0} / T\right)+I=-4.57 \log p_{S_{2}} & +0.92 \log T \\
- & 2.77 \times 10^{-3} T+0.34 \times 10^{5} T^{-2} .
\end{aligned}
$$

The results of the calculations (and plot of $\left[\Delta H_{0} / T\right]+I$ vs $1 / T)$ are given in Table III. Using these values, enthalpy, free energy, and entropy data for the decomposition of $\mathrm{PtS}$ can be calculated, the latter by the equation

$$
\begin{aligned}
\Delta S_{T^{\prime}}{ }^{\circ}=\left(\Delta H_{T}{ }^{\circ}-\Delta{F_{T}}^{\circ}\right) / T & =0.40+0.92 \log T \\
- & 5.54 \times 10^{-3} T-0.34 \times 10^{5} T^{-2}-I .
\end{aligned}
$$

At $298.15^{\circ} \mathrm{K}$, the actual values are

$\Delta H^{\circ}=70.2 \mathrm{kcal}, \Delta F^{\circ}=55.7 \mathrm{kcal}, \Delta S^{\circ}=48.3 \mathrm{cal}^{\circ} \mathrm{K}^{-1}$.

Taking the orthorhombic crystalline phase instead of the diatomic gas for the standard state of sulfur and incorporating the entropies of the elements, ${ }^{14}$ the following values for the standard heat of formation, free energy of formation, and entropy of $\mathrm{PtS}$ are found at $298.15^{\circ} \mathrm{K}$ :

$$
\begin{gathered}
\mathrm{Pt}(\mathrm{s})+\mathrm{S}(\mathrm{rh})=\mathrm{PtS}(\mathrm{s}), \\
\Delta H f^{\circ}=-19.7 \mathrm{kcal}, \quad \Delta F f^{\circ}=-18.3 \mathrm{kcal}, \\
S^{\circ}=13.1 \mathrm{cal}^{\circ} \mathrm{K}^{-1} .
\end{gathered}
$$

The enthalpy and free energy values are in good agreement with those of Kelley ${ }^{11}\left(\Delta H f^{\circ}=-20.18 \mathrm{kcal}\right.$, $\left.\Delta F f^{\circ}=-18.55 \mathrm{kcal}\right)$. The enthalpy is somewhat higher than another estimate ${ }^{15}\left(\Delta H f^{\circ}=-20.8 \mathrm{kcal}\right)$. Biltz

\footnotetext{
${ }^{13}$ K. K. Kelley, "Contributions to the data on theoretical metallurgy. XIII.," U. S. Bureau of Mines Bulletin 584, Washington, D. C. (1960).

${ }^{14}$ D. R. Stull and G. C. Sinke, "Thermodynamic properties of the elements," Advances in Chem. Ser. No. 18, Washington, D. C. (1956)

1 "Selected values of chemical thermodynamic properties," Circular 500, National Bureau of Standards, Washington, D. C 1952.
}

TABLE III. Data for the reaction $2 \mathrm{PtS}(\mathrm{s})=2 \mathrm{Pt}(\mathrm{s})+\mathrm{S}_{2}(\mathrm{~g})$.

\begin{tabular}{lccc}
\hline$T,{ }^{\circ} \mathrm{K}$ & $p_{\mathrm{s}_{2}, \text { atm }}$ & $\left(\Delta H_{0} / T\right)+I$ & $\Delta H_{0} / T$ \\
\hline 1333 & 0.047 & 5.27 & 52.89 \\
1383 & 0.124 & 3.23 & 50.98 \\
1459 & 0.409 & 0.67 & 48.32 \\
\hline
\end{tabular}

In col. $3, \Delta H_{0}=70500 ; I_{\text {mean }}=47.67$.

and Juza's own estimate ${ }^{10}$ is apparently too high $\left(\Delta H f^{\circ}=-16 \mathrm{kcal}\right)$. The entropy is higher than that of Kelley ${ }^{11}$ but agrees almost exactly with that from the low-temperature heat-capacity data of this work. On the basis of the solubility product of $\mathrm{PtS}$ and other data. Zhuk ${ }^{16}$ has reported $\Delta F_{298}{ }^{\circ}=-17.36 \mathrm{kcal}$ and $S_{298}{ }^{\circ}=6.2 \mathrm{cal} \mathrm{gfw}^{-1}{ }^{\circ} \mathrm{K}^{-1}$. The free energy of formation of $\mathrm{PtS}$ from $\mathrm{Pt}$ and $\mathrm{S}_{2}$ gas at high temperatures has been reevaluated from Biltz and Juza's data ${ }^{10}$ by Richardson and Jeffes. ${ }^{17}$ The equation reported, $\Delta F_{T}{ }^{\circ}=-66.100+43.6 T\left(1000-1700^{\circ} \mathrm{K}\right)$, agrees reasonably well with ours over the common range.

For the other monochalcogenides, no published data exist, and standard entropies are estimated for the compounds mentioned in the introduction. Measured values of the entropies of chalcogenides may be well represented by simple additivity of a chalcogen and a metal contribution. Justification will be presented in a forthcoming paper. ${ }^{18}$ The values chosen are in cal $\left.\left(\mathrm{g} \text { atom }{ }^{\circ} \mathrm{K}\right)^{-1}\right]: 10.5$ for the metal $\left(\mathrm{Me}^{2+}\right), 3.0$ for $\mathrm{S}^{2-}$, 7.0 for $\mathrm{Se}^{2--}$, and 9.5 for $\mathrm{Te}^{2-}$. The estimated values are: 1/9 $\mathrm{Rh}_{9} \mathrm{~S}_{8}, 13.2 ; \mathrm{RhTe}, 20.0 ; \mathrm{PdS}, 13.5 ; 1 / 9 \mathrm{Pd}_{9} \mathrm{Se}_{8}$, 16.7; PdSe, 17.5; PdTe, 20.0; PtS, 13.5; $1 / 10 \mathrm{Pt}_{10} \mathrm{Se}_{8}$, 16.1; $\mathrm{Pt}$ Te, 20.0. These values are probably reliable to better than $0.8 \mathrm{cal}\left(\mathrm{g} \text { atom }{ }^{\circ} \mathrm{K}\right)^{-1}$.

\section{ACKNOWLEDGMENTS}

The authors wish to thank The International Nickel Company (Mond), Limited, for the loan of substantial amounts of platinum and palladium to make this study possible. The assistance of Arne Kjekshus in preparing the platinum chalcogenides, and the cooperation of Shu-Sing Chang, Bruce H. Justice, and H. Gary Carlson with the heat-capacity measurements and calculations is thankfully recognized. Fredrik Grønvold expresses his appreciation to Norges Almenvitenskapelige Forskningsråd for assistance. The partial support of the Division of Research of the U.S. Atomic Energy Commission is gratefully acknowledged.

${ }^{16}$ N. P. Zhuk, Zhur, Fiz. Khim. 28, 1523 (1954).

${ }_{17} \mathrm{~F}$. D. Richardson and J. H. E. Jeffes, J. Iron Steel Inst. (London) 171, 165 (1952).

${ }^{18}$ F. Gronvold and E. F. Westrum, Jr. (to be published). 